\title{
Role of Systems Approach in Education
}

\author{
Vikrant Bhaskar $^{1 *}$ Prof. Lajwanti ${ }^{2}$ \\ 1.Senior Research Fellow, Department of Pedagogical Sciences, Faculty of Education, Dayalbagh Educational \\ Institute, (Deemed University), Agra, India. \\ 2.Professor, Department of Pedagogical Sciences, Faculty of Education, Dayalbagh Educational Institute,
}

(Deemed University), Agra, India.

\begin{abstract}
This paper purposes the definition, characteristics, steps, advantages of systems approach and connection of system approach with education. The systems approach was much prevalent in technological, commercial and administrative working systems. The first ever application and development of this concept was done in the field of mechanics and military science, and later, it influenced much physiology and ideologies in sociological and educational sciences. The etymological meaning of the term 'system' is the combination of such things which are controlled and operated by a continually running interaction or mutually dependent processes. A system is an extensive process which includes many concepts in a systematic manner. Any system has the following four basic elements or parameters: Input, Process, Output, and Environment. The systems approach is a team works in which specialists of different subjects (as science, engineering, mathematics, statistics, economics, politics, sociology, accountancy and behavioral sciences) work together. Education, as a system, comprises of evaluation of students, teachers, curriculum, content and instructional objectives in the form of different elements. In the systems approach of education, in the interaction of all these elements, the teaching-learning process is considered responsible for communication and control. In this context, the educational system is formed of teacher, student and instructional programme and a specific type of interaction pattern is developed. The systems approach is becoming more and more important in the field of education too. The educational systems functions for the accomplishment of its specific goals in every nation, and is influenced by the super social system. Education gets all its inputs, outputs, resources and obstacles from the society. The educational system is evaluated in the context of social system. There are several sub-systems in a system, such as educational management, educational administration, educational guidance etc. Under the systems approach, the above eight steps can be adhered to effectively control the entire educational process and educational input, and thus other related educational problems can be solved. In the educational field, the systems approach is an important means to organize and determine different programmes for the better training and development of teachers and students.
\end{abstract}

Keywords- Systems, Approaches, Education

DOI: $10.7176 / \mathrm{JEP} / 10-23-15$

Publication date: August $31^{\text {st }} 2019$

\section{Introduction}

The name of systems approach is not new in the modern age of educational technology. The systems approach was much prevalent in technological, commercial and administrative working systems. The first ever application and development of this concept was done in the field of mechanics and military science, and later, it influenced much physiology and ideologies in sociological and educational sciences. Discussing it, that the systems approach has given birth to such a method the fundamental principle of which is to think, not in small parts, but as a whole. This approach presents a detailed and effective picture of problem and its solution. So, this approach has become quite popular in the present age.

Historically, the systems approach was first used during the Second World War, then it came into use in industry and management, and finally it arrived in the field of education too. It is the strategy to manage, control and improve the process and products of education.

\section{Concept of a System}

The term 'system' indicates arrangement, by which is meant the organization of the systematic whole. In it, each part is related to the, other part clearly, and this forms the whole. In the words of Johnson (1963) "System is an organized complex whole (an assemblage or combination of things or parts) forming together a complex unitary whole."The etymological meaning of the term 'system' is the combination of such things which are controlled and operated by a continually running interaction or mutually dependent processes. A system is an extensive process which includes many concepts in a systematic manner.

According to Allport (1955) "System is an object which is related to some activity, and establishes a type of integration and unity in that activity". Discussing its characteristic, that it is a methodology and whole, which is a systematic arrangement of different elements, and in which these elements are interrelated and interdependent. Basically it is a systematic arrangement of elements working in a specific manner. 
Basic Elements/Parameters of a System

Any system has the following four basic elements or parameters:
1. Input
2. Process
3. Output and
4. Environment

Input: By input is meant that raw material or things which are used in a system in order to manufacture a thing. It is what is put into a system.

Process: A process comprises of all that by which the raw material used as input is changed into the product with the help of available technological knowledge. Input is changed into output by a process. It refers to what goes on in a system.

Output: The modified form of input by a process is called product.

Environment: By environment is meant the circumstances in which a system functions.

The basic elements of a system are being displayed by the following diagram:

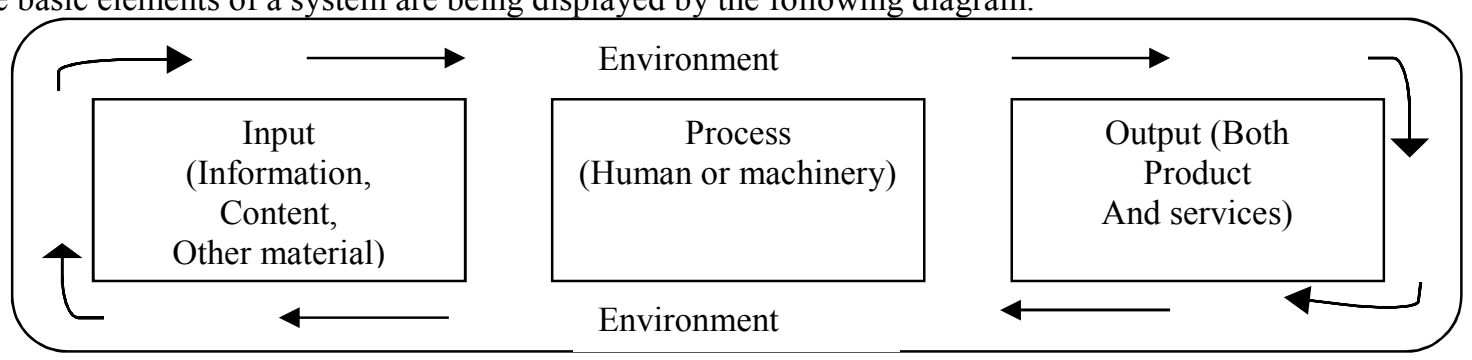

Figure 1. Basic Elements of System

A system draws inputs from the environment and gives output to the environment. A system has to operate within the confines of the environmental context. A system cannot revolt against environmental constraints.

\section{Characteristics of a System}

Following are the important characteristics of a system

1. A system is an integrated and dynamic whole.

2. This is a set of mutually related and mutually dependent elements.

3. All its elements are helpful to realize the main objectives of the system.

4. A system has its definite objectives and goals.

5. The effect of the integrated system is always more than the contribution of its constituent elements. This is a combination of different sub-systems.

6. The parts and sub-parts of a system are mutually related (less or more, directly or indirectly). They are naturally integrated into a whole.

7. A system is not mere combination of its different parts and subparts; rather the arrangement in which they are constructed is more important.

8. Each system has a boundary. This boundary is not visible in a social system, but this helps in establishing proper relationship between system and environment.

9. Each system is divided into two parts by its boundary: (a) closed system and (b) open system.

\section{Meaning of Systems Approach}

The term 'systems approach' has been formed by two words: systems + approach. By systems is meant the entirety or wholeness, in which all elements, factors, organs or components are mutually related, knit together and selfcontrolled. The systems approach believes in the entirety. This approach considers teaching and training as social and technological process. In educational sphere this approach is a method to arrive at solutions to problems, and it helps to carry forward and develop the teaching and training system as per the new changes.

Education in this systems approach is considered good, in which some elements function as input. Then these elements pass through a process and then emerge as output. The output is the product or the realization of objectives. This approach provides education with the level of active product system, and tries to establish education as a product.

\section{Definitions of Systems Approach}

Groups of combinations and interrelated or interacting components forming collective entities are called system (Arnold and Wade, 2015). Different scholars have defined systems approach in different ways, but their chief motive remains the same. Barathy (1958) discussed and described it as common sense by design, which means a systematic arrangement for the analysis and solution of a problem. In his words: "Systems approach to 
instructional design is known as common sense by design' a systematic way of analyzing a problem and solving it."

Twelker et al. (1969) said that "Systems approach is a management tool that allows individuals to examine all aspects of the problem, to inter-relate the effects of one set of decisions to another, and to optimally use the resources at hand to solve the problem. In the words of Kumar (2009) "Systems approach is a term used to describe the systematic application of educational technology to an educational or training problem, starting with the input (entering behavior) and output (terminal behavior) how best to progress from the former to the latter."

Khanna et al. (1998) reported that "The systems approach involves the accurate identification of the requirements and problems, the setting of objectives after identifying their needs in performance oriented terms, the application of logic and analysis techniques to the problems, the development of methods for the solution of the problems and the rigorous measurement of the product against specific performance objectives. "In systems approach, education is a rational problem-solving process and it is also called the approach for getting systematic knowledge about the teaching-learning process.

Characteristics of Systems Approach- Following are the characteristics of Systems Approach

1. It provides a suitable basis for the determination of objectives from analysis of environment system.

2. Instructional objectives are so set by which their accomplishment can be observed easily.

3. It is a holistic and interdisciplinary approach.

4. Selection of instructional strategies and transmission method Plays an important role in this approach.

5. It is applicable to almost in every situation whether academic or administration.

6. The systems approach is integrated and dynamic.

7. The systems approach is a systematic arrangement of elements which functions in a specific manner.

8. This makes use of human resource, finance, machinery and material for problem solving in an effective manner.

\section{Steps of Systems Approach}

The chief steps of systems approach are being given below:

1. Systems Analysis: In this, the needs, means, elements, functions; processes etc. of the system are analyzed. This analysis is done in the context of input, output, process and environment. Its two chief functions are.

A) To determine what objectives the system will accomplish.

B) To analyze the methodology of each component through the needs and elements of the system as per the objectives.

C) This analysis is done as per the available environment

2. Systems Design: This is the stage of item synthesis. At this step, the goal of system is kept in view. At this level, different methods are suggested as per the objectives, by which the system can present output in a most effective manner. Three chief processes at this step are:

A) Determining objectives and goals of the system.

B) Selecting proper methods, strategies, approaches and devices.

C) Constructing a comprehensive programme for the working of system as related to its objectives and different elements. In this plan, the input, output and process and environment of the system are included and explained.

3. Systems Operation and Evaluation: At this step, it is determined if the system is capable of accomplishing its objectives or not. For this, the system is tested under simulated circumstances in order to see its validity and utility. This is called formative evaluation of the system. According to it, feedback is used to effect necessary changes, amendments and modifications to the structure, as a result of which (the system becomes more efficient. Thus, this process of improvement continues until there is any possibility of improvement for the accomplishment of objective.

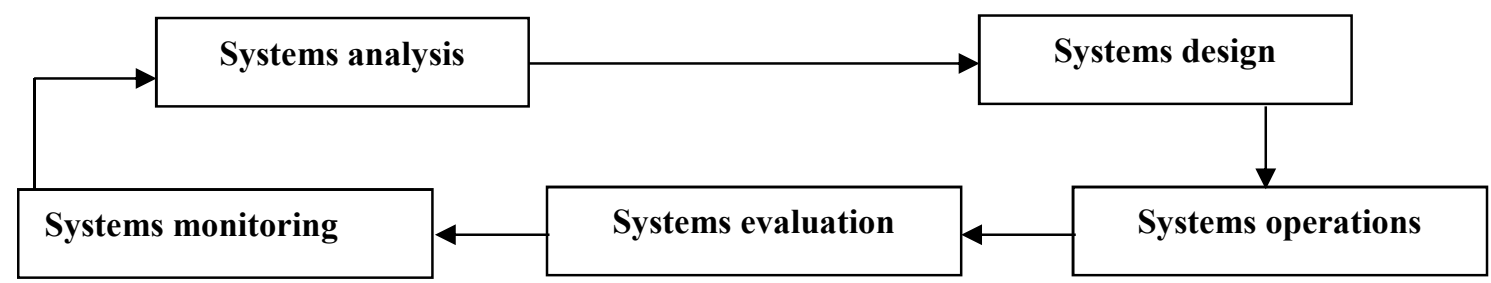

Figure. 2. Steps of Systems Approach

4. Systems Monitoring: Under this, the method being executed is monitored from time to time and its utility is examined. 


\section{Systems Approach as an Interdisciplinary Approach}

The systems approach is a team works in which specialists of different subjects (as science, engineering, mathematics, statistics, economics, politics, sociology, accountancy and behavioral sciences) work together. Discussing systems approach, Srivastav (1988) has said that in it, a system concept and thinking is applied. This is a type of ideology in which a problem is looked at, understood and analyzed as an integrated whole. In this approach, predetermined objectives are inherent in the components and sub-components for mutual interaction in organized mutual cooperation. In this approach, several sub-systems are interrelated such in a predetermined format or design that it can work as an integrated system, and thus go on to achieve the systems objectives effectively. When the systems achieve its predetermined objectives, only then it is called a successful systems approach; else it or its components and sub-components are suitably modified in order to amend and improve its format.

On the basis of above analysis, it can be said in the words of Kulshreshtha (1998): Systems approach is a concept or educational tool which makes educational functions or challenges more successful, integrated, responsive, responsible, logical, systematic, automatic and flexible In it, the logical problem-solving method is used to analyze each aspect of the educational process, predetermined objectives are evaluated and then the analyzed elements (aspects) are synthesized in order to achieve integration.

Problem-solving is inherent in the systems approach. Generally the systems approach is a process in which needs and problems of a system are identified, then the problem is selected, and then the most suitable alternative for problem-solving is selected, the obtained solution and outcome are evaluated, and necessary amendments are effected, if necessary. The greatest characteristic of this system is that it does not analyze elements separately; rather it analyzes them on this integrated basis aimed at problem-solving. In this, the process synthesis is important together with the process of analysis. The systems approach carries an individual from the part to the whole.

Discussing the systems approach, R.P. Bhatnagar (1996) has concluded that this is a logical problem-solving process which identifies and studies chief educational problems and its alternatives, and thus arrives at their solution. In other words, the systems approach is a tool which solves educational problems effectively and efficiently; this is an art of reflection which presents problem-solving in a scientific manner.

\section{Education as a System}

Education, as a system, comprises of evaluation of students, teachers, curriculum, content and instructional objectives in the form of different elements. In the systems approach of education, in the interaction of all these elements, the teaching-learning process is considered responsible for communication and control. In this context, the educational system is formed of teacher, student and instructional programme and a specific type of interaction pattern is developed.

Education always uses that latest ideology and technology which is helpful to enhance the quality of education. The systems approach is a technology which contributes in discovering most effective, cost efficient and intelligent methods. Finn (1960), Hoban (1962) and Heinrich (1970) have strongly advocated looking at education as systems approach.

\section{Systems Approach in Education}

The systems approach is becoming more and more important in the field of education too. The educational systems functions for the accomplishment of its specific goals in every nation, and is influenced by the supra social system. Education gets all its inputs, outputs, resources and obstacles from the society. The educational system is evaluated in the context of social system. There are several sub-systems in a system, such as educational management, educational administration, educational guidance etc. These sub-systems function as interdependent elements for the accomplishment of definite objectives and activities. Interactions keep taking place among all these sub-systems, and they contribute in the accomplishment of the wider goals of the supra educational system as a whole.

\section{Stages or Steps of System Approach in Education}

The various stages in the systems approach-

\section{(a) Consider target population characteristics and topic area}

The range of backgrounds, knowledge, attitudes and skills of students coming on to the course will have a strong influence on course design. Pre-knowledge and any common misconceptions will have to be catered for in the design of the course (these may, for example, affect sequence, structure and support mechanisms).

\section{(b) Estimate relevant existing skills and knowledge of learners}

There may be minimum standards of entry to the course, but this will not always be so. For example, the increasing numbers of non-standard and mature student entrants to higher education will not necessarily have conventional paper qualifications, but may possess skills and qualities which will have an influence on course design. This may have implications for teaching methods, bridging courses, support systems etc. 


\section{(c) Formulate objectives/learning outcomes}

The objectives and learning outcomes of the course or curriculum element will attempt to encapsulate the new skills, knowledge or attitudes which it is intended that the students will acquire. They may be

formulated by the learners themselves, by employers, by teaching staff, by a validating, examining or professional body, or by some combination of these and other sources.

(d) Select appropriate instructional methods

Having specified the objectives and learning outcomes, we should be in a better position to select appropriate teaching/learning methods through which objectives have a reasonable chance of being achieved .There are far more teaching methods available to choose from than most people realize.

(e) Operate course or curriculum

The next element in the system is the actual implementation of the course. This involves all the logistical arrangements associated with running the course, including overall structuring, pacing, implementing the chosen teaching strategies, using appropriate supportive media and materials, and ensuring that all aspects of the course run as smoothly as possible.

\section{(f) Assess and evaluate}

The assessments should be closely related to the specified course objectives and learning outcomes. Poorlyachieved objectives or learning outcomes should lead the course designers to examine the entire system in order to identify places where improvements might be made. This could involve a change in the objectives and learning outcomes, a revised assessment of students' pre-knowledge and a critical review of the instructional methods used. These deliberations, together with feedback on the course from staff, students, employers, etc, can be used in an evaluation of the entire concept of the course, which should, in turn, form the basis of an on-going cyclical course development process. If a teacher wants to apply the instructional systems approach in the field of education, then he will have to apply a systematic methodology for each step. He will have to follow the eight steps as displayed.

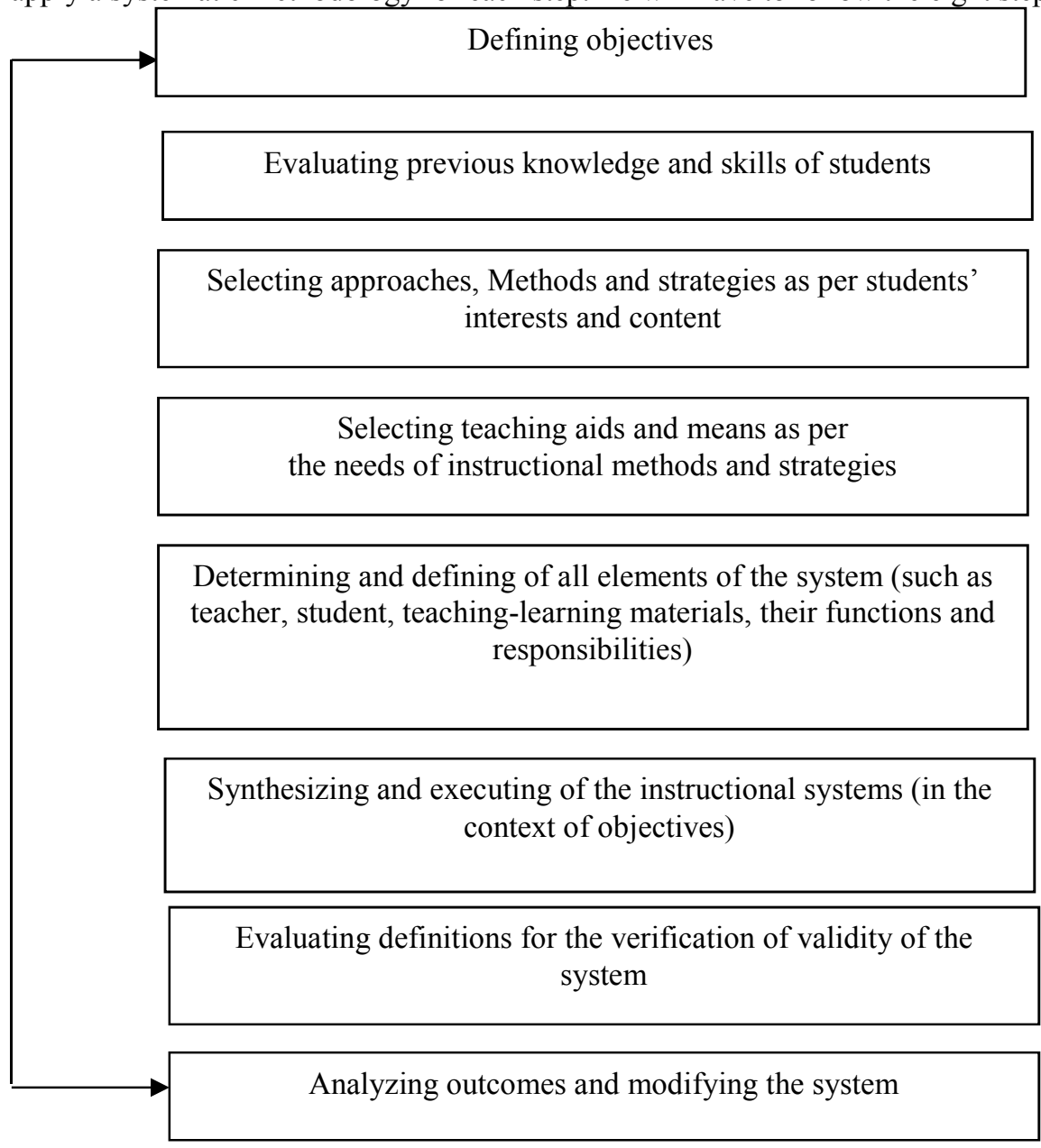

Figure. 3. Steps of the Systems Approach in Education 


\section{Advantages of Systems Approach in Education}

1

-A teacher understands the basic teaching process by systems approach.

- This is helpful in the construction of directive material.

- This system proceeds towards constructing suitable educational environment by investing educational enterprises.

- This clarifies objective and means.

5

- This enhances efficiency in guidance process.

- Learning experiences can be provided properly by the systems approach.

- The systems approach helps to make educational administration, educational system and
educational instruction more effective.

- This is help in the integration of machine, human and communication, such that the objectives can be accomplished.

- Evaluation takes place, directly or indirectly, at every step, by which suitable changes can be effected to it.

- The systems approach is flexible and can be modified as may be needed.

\section{Figure. 4. Flow Chart: Advantages of Systems Approach}

\section{Conclusion}

Under the systems approach, the above eight steps can be adhered to effectively control the entire educational process and educational input, and thus other related educational problems can be solved. In the educational field, the systems approach is an important means to organize and determine different programmes for the better training and development of teachers and students and help in providing the quality of education.

\section{References}

Agarwal, J. C. (1996). "Essentials of Educational Technology; Teaching Learning (Innovations in Education)", Vikas Publishing House Pvt. Ltd. New Delhi.

Allport, F. (1955). "Theories of Perception and the Concept of Structure: John Wiley \& Sons", New York. Arnold, R. \& Wade J. (2015) “A Defintion of systems thinking”. Procedia computer science. 44 669-678 Finn, J. D. (1960). "Technology and the instructional process". AV Communication Review, 8, 5-26. Gronlund, N. E. (1970). "Stating Behavioural objectives for classroom Instruction", Macmillan Co. London. Heinich, R. (1970). "Technology and the management of instruction". Washington, D.C: Association for Educational Communications and Technology, 1970.

Hoban, C. F. (1962). "Research in new media in education". Paper presented to the American Association of Colleges for Teacher Education, Washington, D.C.

Johnson, R. A. (1963). “The Theory and Management of Systems: McGraw-Hill Book Company”, Inc., New York. 
Khanna, et al. (1998). "Education in the Emerging Indian Society (Made Easy)", Delhi: Doaba House.

Kulshrestha, S. P. (2010). "Foundations of Educational Technology”, R. Lall Book Depot Near government Inter College, Meerut.

Kumar A. (2009). “Operations Management: New Age Institutional Pvt. Ltd.”, Bangalore

Kumar, K. L. (1996). "Educational Technology, New Age”, New Delhi.

Mathur, S. S. (1996). "Educational Technology”, Vinod Pustak Mandir, Agra

Mohanty, S. B. (1986). "Educational Technology", Kalyani, New Delhi.

Mohanty, J. (1992). "Educational Technology", Deep \& Deep, New Delhi.

Ober, R. L. \& Ernest, L. B. (1971). "Systematic observation of Teaching”, Prentice Hall, New Jersy.

Pangotra, N. (1980). "Fundamentals of Educational Technology", International Publishers, Chandigarh.

Sharma, R. A. (1996). "Educational Technology”, R. Lall Meerut.

Twelker, A. (1969). "Classroom simulation and teacher preparation”, The School Review, 1167, 75, 197-204.

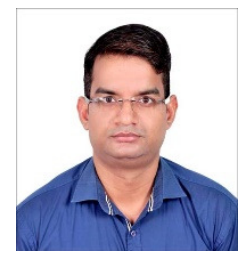

Vikrant Bhaskar is Senior Research Fellow (SRF), Ph.D. in Dept. of Pedagogical Sciences, Faculty of Education, Dayalbagh Educational Institute, Dayalbagh, Agra, India. His Academic profile covers M.Phil. (Education) along with M.Ed. (Education), with the renowned UGC-NET-JRF (Education). He has done M.Sc. (Mathematics) and M.A (Political Science) in his post-graduation, along with a PG Diploma in Computer Sciences and Application. Currently he is pursuing Post Graduate Diploma in Education Technology from IGNOU. In his Graduation he has done B.Sc. (PCM). He has published many research papers in various journals and attended various seminar/conferences, workshops and symposium along with the faculty development programme at national and international level.

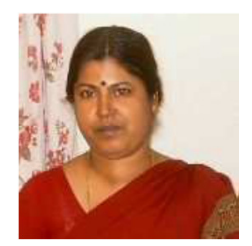

Prof. Lajwanti is born in Agra, India. She is working in the Dept. of Pedagogical, Faculty of Education, Dayalbagh Educational Institute, Dayalbagh, Agra, India since last 20 years. Presently, she is Professor and working in the area of students' psychology. She published more than 40 research paper in various reputed journals and peer reviewed conferences. She is Life Member of many societies and body like Psycho-Linguistic Association of India (PLAI), Agra, All India Association for Educational Research (AIAER), System Society of India (SSI), Council of Behavioural Scientists, and Council for Teacher Education (CTE), Delhi. 